\title{
Potencial de melhoramento e divergência genética de cultivares de milho-pipoca(1)
}

\author{
Glauco Vieira Miranda ${ }^{(2)}$, Ronaldo Rodrigues Coimbra(2), Cleiton Lacerda Godoy ${ }^{(2)}$, Leandro Vagno Souza(2), \\ Lauro José Moreira Guimarães ${ }^{(2)}$ e Aurélio Vaz de Melo(2)
}

\begin{abstract}
Resumo - O objetivo deste trabalho foi avaliar o potencial de melhoramento e a divergência genética de nove cultivares tropicais de milho-pipoca. A divergência genética foi estimada por meio da técnica de análise multivariada e as cultivares foram agrupadas com base na distância generalizada de Mahalanobis (DGM), utilizando o método de otimização de Tocher e a dispersão gráfica. Com produtividade de grãos acima de 3 t/ha, destacaram-se as cultivares CMS 43, IAC 112, Viçosa, CMS 42 e Branco, e com índices de capacidade de expansão acima de 24 (v/v), as cultivares IAC 112, RS 20 e Zélia. As estimativas da DGM indicaram (RS 20 e Beija-flor) e (Rosa-claro e RS 20) os pares de cultivares mais distantes geneticamente, e (IAC 112 e Viçosa) e (Branco e CMS 42), os pares mais similares. Foram identificados três ou quatro grupos divergentes dependendo do método de agrupamento. Para o melhoramento de milho-pipoca, as cultivares com maiores potenciais são RS 20, Zélia, IAC 112 e Beija-flor. As cultivares apresentam divergência genética.
\end{abstract}

Termos para indexação: Zea mays, seleção, análise multivariada, método de melhoramento.

\section{Potential to breeding and genetic divergence in popcorn cultivars}

\begin{abstract}
The objective of this paper was to evaluate the potential of breeding and genetic divergence in nine tropical popcorn cultivars. The genetic divergence was estimated using multivariate analysis techniques and the cultivars were grouped based in Mahalanobis' generalized distance (MGD), using Tocher's optimization and graphic dispersion. The best cultivars concerning the yield grain above 3 ton/ha were CMS 43, IAC 112, Viçosa, CMS 42 and Branco, and to popping expansion above $24(\mathrm{v} / \mathrm{v})$ were IAC 112, RS 20 and Zélia. The estimates of MGD indicated the pairs genetically more distant (RS 20, Beija-flor) and (Rosa-claro, RS 20) as well as pairs genetically more similar (IAC 112, Viçosa) and (Branco, CMS 42). Tree or four genetic divergences groups were formed depending on the method. To popcorn breeding, cultivars with best potential are RS 20, Zélia, IAC 112, and Beija-flor. The cultivars show genetic divergence.
\end{abstract}

Index terms: Zea mays, selection, multivariate analysis, breeding methods.

\section{Introdução}

No melhoramento de milho-pipoca, os interesses dos agricultores, da agroindústria e dos consumidores devem ser considerados (Brunson \& Smith, 1945). As principais características das plantas e grãos para o melhoramento genético são a alta produtividade, o

\footnotetext{
(1) Aceito para publicação em 10 de fevereiro de 2003.

(2) Universidade Federal de Viçosa, Dep. de Fitotecnia, Avenida P. H. Rolfs, s/n, CEP 36570-000 Viçosa, MG.

E-mail: glauco@ufv.br, coimbrarr@bol.com.br, becofc@bol.com.br, vagnosouza@bol.com.br, lauroguimaraes@bol.com.br, vazdemelo@bol.com.br
}

baixo acamamento e quebramento das plantas, a alta resistência às doenças e às pragas, a alta capacidade de expansão e boas características organolépticas como maciez, sabor, aroma e cor da flor da pipoca (Alexander \& Creech, 1977).

A capacidade de expansão (CE) dos grãos de milho é a característica mais importante para o consumidor e pode ser definida como a relação entre o volume de pipoca e o volume de grãos ou ainda a relação entre o volume de pipoca e o peso de grãos (Alexander \& Creech, 1977). Quanto maior a capacidade de expansão, melhor é a qualidade da pipoca. A capacidade de expansão pode atingir o índice de 45 em cultivares americanas (Sawazaki, 1996). 
No entanto, cultivares com índices de CE acima de 15 são consideradas comerciais pelas normas brasileiras (Zinsly \& Machado, 1987). A maciez da pipoca está altamente relacionada com a capacidade de expansão (Sawazaki, 1995).

A capacidade de expansão é uma característica poligênica em germoplasma tropical de milho-pipoca, com as estimativas da herdabilidade variando de 70\% a 90\% (Lira, 1983; Linares, 1987; Zanette, 1989; Andrade, 1996; Pacheco et al., 1998; Coimbra et al., 2001; Pereira \& Amaral Júnior, 2001). É afetada pelo equipamento de avaliação, pelo conteúdo de umidade do grão, por danos no pericarpo e endosperma, teor de umidade do grão, secagem e grãos imaturos (Dofing et al., 1991; Machado, 1997). A produtividade de grãos está inversamente correlacionada com a CE (Sawazaki, 1995; Coimbra et al., 2001). Isto dificulta o ganho de seleção simultâneo quanto às duas características no melhoramento populacional.

No melhoramento de milho-pipoca, diferentes germoplasmas têm sido utilizados a fim de aumentar o valor das características de interesse comercial. No Brasil, tem-se utilizado o cruzamento entre cultivares locais (Lira, 1983; Linares, 1987; Andrade, 1996), ou as gerações avançadas de híbridos americanos (Zanette, 1989; Coimbra, 2000). Em países de clima temperado, têm-se utilizado cruzamentos do milho-pipoca com o milho duro, e a seleção é realizada exclusivamente quanto à capacidade de expansão; retrocruzamentos sucessivos do milho-pipoca com linhagens elites heteróticas de milho comum também são realizados. Larish \& Brewbaker (1999) constataram a viabilidade do uso de cruzamentos de germoplasma originados de países temperados com milho-pipoca tropicais.

No Brasil, as cultivares de milho-pipoca não são distribuídas em grupos heteróticos complementares para a obtenção de híbridos, como ocorre com o milho comum. Em trabalho realizado nos EUA, Larish \& Brewbaker (1999) identificaram três grupos heteróticos no início do programa de melhoramento de milho-pipoca.

As populações de milho com potencial para serem utilizadas como genitoras em programas de melhoramento intrapopulacionais devem possuir altas médias e ampla variabilidade genética quanto às características de interesse (Hallauer \& Miranda Filho, 1987).
As populações de milho-pipoca brasileiras são pouco melhoradas, apresentam grande depressão endogâmica - dificultando a obtenção de linhagens -, alta suscetibilidade à helmintosporiose e à ferrugem, baixa qualidade de colmo e baixa capacidade de expansão dos grãos (Andrade, 1996; Coimbra, 2000).

As análises de divergência genética visam à identificação de genitores para a formação de populações com variabilidade genética e conseqüente ganho genético em ciclos sucessivos de seleção. Como a divergência genética pode estar associada à heterose, as análises de divergência genética podem ser úteis para a predição preliminar de cruzamentos que otimizem a heterose. Em estudos preditivos da divergência genética com base em marcadores moleculares, Melchinger (1999) afirmou que numerosos estudos experimentais demonstraram que, com número suficiente de RFLP (Restriction Fragment Length Polymorphism), SSR (Simple Sequence Repeat) ou AFLP (Amplified Fragment Length Polymorphism), foi possível obter a relação entre os acessos, caracterizar grupos heteróticos, identificar novos grupos heteróticos de maneira sistemática, relacionar linhagens de procedência desconhecida com os grupos heteróticos, e monitorar a diversidade genética entre cultivares melhoradas em uso e em coleções de germoplasma.

A divergência genética pode ser avaliada por meio de técnicas multivariadas ou processos preditivos. Por dispensarem a obtenção de híbridos, os métodos preditivos da divergência genética têm merecido considerável ênfase. Estes tomam por base diferenças entre características que possuem comportamento quantitativo, geralmente usando medida de dissimilaridade como as distâncias Euclidianas ou de Mahalanobis (Rao, 1952).

O objetivo deste trabalho foi avaliar o potencial de melhoramento e estimar a divergência genética de nove cultivares de milho-pipoca.

\section{Material e Métodos}

Entre oito ensaios conduzidos durante dois anos, com quatro épocas de semeadura, foi escolhido o que apresentava a menor interação das cultivares com os ambientes, determinada por meio da análise multivariada AMMI BIPLOT (Namorato et al., 2002). Esse ensaio foi instalado na Estação Experimental de Coimbra, da Universidade Federal de Viçosa, em 15 de outubro de 1998. 
Foi utilizado o delineamento experimental em blocos ao acaso com quatro repetições. Cada parcela foi composta por quatro linhas de $4 \mathrm{~m}$ de comprimento. O espaçamento entre fileiras foi de $0,90 \mathrm{~m}$. Nas parcelas, a semeadura foi feita em covas com espaços de $0,25 \mathrm{~m}$, com uma planta por cova, de forma que cada parcela ficou com 64 plantas, constituindo população estimada em 45.000 plantas/ha.

As cultivares de milho-pipoca avaliadas foram Beijaflor, Branco, CMS 42, CMS 43, IAC 112 (comercial), Rosa-claro, RS 20 (comercial), Viçosa e Zélia (comercial). As populações Beija-flor, Branco, Rosa-claro e Viçosa pertencem à Universidade Federal de Viçosa; CMS 42 e CMS 43, à Embrapa; RS 20, comercializada pela Agroeste; IAC 112, ao Instituto Agronômico; e Zélia, à Pioneer Hibreeds.

Foram avaliadas as seguintes características em cada parcela experimental: altura de planta (média de seis plantas por parcela), altura de espiga (média das mesmas seis plantas por parcela usadas para medir a altura de planta), estande por parcela, número de espiga por parcela, empalhamento (média de seis espigas por parcela), número de espigas doentes, capacidade de expansão e produtividade de grãos. A prolificidade foi obtida pelo número de espiga por parcela e estande por parcela.

O empalhamento foi avaliado de acordo com a seguinte escala (Centro Internacional de Mejoramiento de Maíz y Trigo, 1985): 1: espiga completamente empalhada; 2: pequena abertura da palhada na ponta da espiga, sem expor o sabugo; 3: sabugo exposto na ponta da espiga; 4: presença de grãos expostos na ponta da espiga; e 5: ampla exposição de grãos com ampla abertura da palhada.

A severidade de helmintosporiose foi avaliada em oito plantas por parcela, a partir do início do florescimento, com intervalo de 14 dias. Foi utilizada a seguinte escala de notas (Centro Internacional de Mejoramiento de Maíz y Trigo, 1985): 1: ausência de sintomas; 2: lesões esparsas nas folhas inferiores; 3 : até $50 \%$ das folhas com lesões, sendo severas em $25 \%$ das folhas inferiores; 4 : até $75 \%$ das folhas com lesões, sendo severas em $50 \%$ das folhas inferiores; e 5: até $100 \%$ das folhas com lesões, sendo severas em $75 \%$ das folhas inferiores.

A capacidade de expansão dos grãos de milho-pipoca foi obtida pela razão entre o volume da pipoca expandida e o volume dos grãos crus. De cada parcela, uma amostra de $30 \mathrm{~mL}$ de grãos, medida em proveta graduada de $100 \mathrm{~mL}$, foi estourada em pipoqueira elétrica com controle automático de temperatura, regulada à temperatura de $237^{\circ} \mathrm{C}$, sem utilização de óleo, gorduras ou sal. O volume da pipoca expandida foi medido em proveta graduada de $1.000 \mathrm{~mL}$.
A análise multivariada empregada na avaliação da divergência genética entre as cultivares foi a análise canônica e de agrupamento com base na Distância Generalizada de Mahalanobis. O agrupamento das cultivares foi realizado pelo Método de Otimização de Tocher, seguindo o critério de que a variância entre as cultivares não poderia ser maior dentro dos grupos do que entre os grupos. Todas as análises foram realizadas de acordo com Rao (1952) e Cruz \& Regazzi (1994).

As análises de variância, bem como todas as análises multivariadas, foram realizadas utilizando-se o Programa Genes (Cruz, 1997).

O potencial de melhoramento das cultivares foi determinado pelas médias das características agronômicas mais importantes; a posição das cultivares em diferentes grupos foi obtida pela divergência genética.

\section{Resultados e Discussão}

Os efeitos das cultivares de milho-pipoca foram significativos pelo teste $\mathrm{F}$ quanto a todas as características, o que revela a variabilidade genética (Tabela 1).

As cultivares de milho-pipoca apresentaram o número de dias para florescimento característico de ciclo normal para o milho comum, apesar de normalmente as plantas de milho-pipoca florescerem mais cedo. Na formação de populações mais precoces, as cultivares RS 20 ou Branco são as mais indicadas, e de populações tardias, a CMS 43, Viçosa, Beija-flor, Rosa-claro e Zélia.

A helmintosporiose é uma das doenças mais comuns no milho-pipoca (Fantin et al., 1991). Nas três épocas de avaliação, as cultivaraes IAC 112, Branco, CMS 43 e Beija-flor foram as mais tolerantes. As outras cultivares comerciais, RS 20 e Zélia, apresentaram alta suscetibilidade a essa doença, maior até do que as populações locais Beija-flor, Rosa-claro e Viçosa. A suscetibilidade das populações de milho-pipoca às doenças é comum (Bleicher, 1988; Fantin et al., 1991; Miranda et al., 2002).

Em milho-pipoca, as características altura de plantas e de espigas são altamente correlacionadas (Coimbra et al., 2001) e indicadoras de grandes diferenças entre as cultivares. A cultivar RS 20 destacou-se como a mais baixa e a CMS 43 como a mais alta. Pacheco et al. (1998), trabalhando com diversas populações, encontraram altura de plantas variando 
de $1,50 \mathrm{~m}$ a $2,50 \mathrm{~m}$ e altura de espiga variando de $0,80 \mathrm{~m}$ a $1,50 \mathrm{~m}$. A proporção entre altura de planta e altura de espiga foi praticamente semelhante nas cultivares, com destaque da menor relação na RS 20 e a maior na CMS 43. A altura de planta extrema e a alta proporção entre altura de plantas e altura de espigas podem fazer com que a cultivar apresente maior suscetibilidade ao acamamento, não sendo indicada para cultivo em locais com grande intensidade de ventos e com solos férteis, que faz com que a planta cresça em demasia.

A qualidade de colmo é uma das mais importantes características do milho-pipoca para a produção em larga escala, com colheita mecanizada. A qualidade do colmo pode ser avaliada pela porcentagem das plantas acamadas e quebradas. Destacaram-se como as cultivares com as melhores qualidades de colmo a IAC 112, a Branco e a CMS 42. Tanto as populações quanto as cultivares melhoradas apresentaram altos valores em relação à porcentagem de plantas acamadas e quebradas. Pacheco et al. (1998) encontraram valores de até $26 \%$ de plantas acamadas e quebradas nas populações CMS 42 e CMS 43.

Portanto, considerando o conjunto de características relacionadas aos estádios vegetativos, destaca-se a cultivar IAC 112, com o padrão mais próximo dos híbridos modernos de milho comum. No entanto, outras características de interesse também se encontram em populações melhoradas de polinização aberta, como a precocidade em RS 20, e não melhoradas, como a baixa incidência de helmintosporiose em Beija-flor e Branco.

A diferença entre a prolificidade ocorreu em virtude do número de espigas por parcela, já que o número de plantas por parcela foi estatisticamente semelhante entre as cultivares (Tabela 2). A prolificidade é característica comum em plantas de milhopipoca (Brunson \& Smith, 1945). A densidade populacional afeta também o tamanho de grãos, que é relacionado com o tamanho da flor de pipoca.

O empalhamento da espiga sem exposição do sabugo ou grãos confere maior proteção contra o ataque de carunchos e de traças no período entre a maturação e a colheita (Machado, 1997). A palha também protege os grãos da radiação solar, evitando que sejam submetidos às altas temperaturas nas horas mais quentes do dia, causando secamento rápido e trincamento do endosperma. O empalhamento também é importante para a qualidade do milho-pipoca. De maneira geral, as cultivares apresentaram bom empalhamento, sendo superiores a IAC 112, a RS 20 e a CMS 43.

A porcentagem de espigas doentes é uma característica importante do milho-pipoca, uma vez que

Tabela 1. Número de dias para florescimento (FLO), severidade de helmintosporiose no florescimento (HT1), aos 14 dias após florescimento (HT2) e aos 28 dias após florescimento (HT3), altura de plantas (AP, cm), altura de espigas $(\mathrm{AE}, \mathrm{cm})$, proporção $\mathrm{AP} / \mathrm{AE}$, porcentagem de plantas acamadas $(\mathrm{PAC})$ e porcentagem de plantas quebradas $(\mathrm{PPQ}) \mathrm{em}$ nove cultivares de milho-pipoca.

\begin{tabular}{|c|c|c|c|c|c|c|c|c|c|}
\hline Cultivar & FLO & $\mathrm{HT}^{(1)}$ & $\mathrm{HT}^{(1)}$ & $\mathrm{HT}^{(1)}$ & $\mathrm{AP}$ & $\overline{\mathrm{AE}}$ & $\mathrm{AP} / \mathrm{AE}$ & PAC & PPQ \\
\hline Beija-flor & 69 & 2,3 & 2,1 & 2,3 & 184 & 98 & 0,5 & 7,5 & 5,4 \\
\hline Branco & 63 & 1,9 & 1,8 & 3,6 & 173 & 85 & 0,5 & 0,0 & 3,6 \\
\hline CMS 42 & 68 & 2,4 & 2,5 & 2,8 & 178 & 98 & 0,5 & 2,4 & 2,4 \\
\hline CMS 43 & 69 & 2,0 & 2,0 & 2,2 & 199 & 112 & 0,6 & 3,2 & 3,6 \\
\hline IAC 112 & 64 & 1,7 & 2,1 & 2,4 & 181 & 83 & 0,5 & 1,4 & 0,0 \\
\hline Rosa-claro & 69 & 2,5 & 2,4 & 2,6 & 182 & 93 & 0,5 & 4,7 & 6,9 \\
\hline RS 20 & 63 & 2,9 & 2,9 & 3,5 & 138 & 61 & 0,4 & 1,6 & 12,4 \\
\hline Viçosa & 70 & 2,6 & 2,3 & 2,5 & 177 & 95 & 0,5 & 5,8 & 2,3 \\
\hline Zélia & 69 & 2,8 & 2,6 & 3,0 & 162 & 81 & 0,5 & 6,3 & 2,6 \\
\hline Média & 67 & 2,3 & 2,3 & 2,8 & 174 & 90 & 0,5 & 3,7 & 4,4 \\
\hline QM Tratamentos & $16.948^{* *}$ & $0,123^{*}$ & $0,0999 *$ & $0,010^{\mathrm{ns}}$ & $55.293 * *$ & $2.576,5 * *$ & $0,040 * *$ & $0,00491^{*}$ & $0,00171^{\mathrm{ns}}$ \\
\hline $\mathrm{CVg}^{(2)}$ & 4,51 & 12,86 & 12,40 & - & 9,96 & 16,92 & 8,29 & 54,92 & - \\
\hline $\mathrm{CVe}^{(3)}$ & 2,04 & 13,01 & 13,59 & 29,15 & 3,62 & 7,30 & 6,25 & 80,6 & 134 \\
\hline
\end{tabular}

(1) 1: ausência de sintomas; 2 : lesões esparsas nas folhas inferiores; 3 : até $50 \%$ das folhas com lesões, sendo severas em $25 \%$ das folhas inferiores; 4 : até $75 \%$ das folhas com lesões, sendo severas em $50 \%$ das folhas inferiores; 5 : até $100 \%$ das folhas com lesões, sendo severas em $75 \%$ das folhas inferiores.

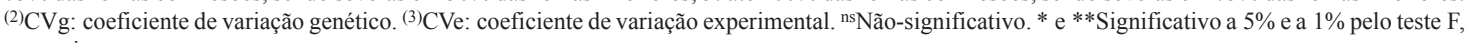
respectivamente. 
existe a necessidade de estarem livres de toxinas, e afeta negativamente a capacidade de expansão (Machado, 1997). Todas as cultivares apresentaram pelo menos $10 \%$ de suas espigas com algum tipo de doença.

O peso de 100 grãos é característica correlacionada positivamente com a produtividade de grãos e negativamente com a capacidade de expansão (Sawazaki, 1995). Entre as cultivares, destacou-se a RS 20, com os grãos menores, e Rosa-claro e Beijaflor, com os mais pesados. Carneiro (2002) avaliou o peso de 100 grãos da população de polinização aberta DFT 2 e constatou que apresentavam valor de 10,12 a 16,03 , correspondente às peneiras $13 \mathrm{e} 17$, indicando que para plantio de um hectare é necessário no máximo $9 \mathrm{~kg}$ de sementes comerciais.

A capacidade de expansão é a principal característica considerada na avaliação da qualidade de milho-pipoca. Destacaram-se as cultivares comerciais IAC 112, RS 20 e Zélia, com índices acima de $24(\mathrm{v} / \mathrm{v})$. Diversos autores têm encontrado índices de CE variando de 10 a 40. Em populações locais, os índices foram mais baixos (por volta de 15, v/v), como encontrado por Andrade (1996) em ensaios conduzidos em 1990. No Ensaio Nacional de Milho-Pipoca, realizado em 1991/1992, o índice médio foi de 17,5 (v/v) e o maior de 20,8 (v/v) (Sawazaki, 1995).
Zanette (1989) encontrou índice médio de 24,73 (v/v); Pacheco et al. (1998), 16,85 (v/v); Coimbra et al. (2001), 19,7 (v/v) e Galvão et al. (2000), $36(\mathrm{v} / \mathrm{p})$. Ainda relacionado à qualidade da pipoca, $\mathrm{o}$ milho da cultivar Rosa-claro produz pipoca com pericarpo escuro, proporcionando-lhe aspecto não comercial, apesar do endosperma mostrar a cor bastante branca, ao contrário de outras cultivares que possuem a cor amarela. Outro aspecto relacionado à qualidade da pipoca é o pericarpo quebradiço na pipoca estourada. Esse aspecto proporciona menores resíduos de casca após a ingestão.

A produtividade média de grãos das cultivares foi adequada para o milho-pipoca. Destacaram-se CMS 43, IAC 112, Viçosa, CMS 42 e Branco, todas acima de $3.000 \mathrm{~kg} / \mathrm{ha}$. Tais produtividades estão próximas das encontradas por diversos autores, tais como Andrade (1996), Sawazaki (1996), Galvão et al. (2000) e Coimbra et al. (2001). Para a agroindústria, a produtividade de grãos e outras características correlacionadas são secundárias em relação à qualidade e quantidade da pipoca.

Apenas duas variáveis canônicas foram suficientes para representar $96,558 \%$ da variância genética das cultivares, não sendo necessária a utilização de nenhuma outra variável canônica (Cruz \& Regazzi, 1994) (Tabela 3).

Tabela 2. Número de espigas por parcela (NE), estande final por parcela (EF), prolificidade (PLF), nota de empalhamento (EMP), porcentagem de espigas doentes (PED), peso de 100 sementes (P100, g), capacidade de expansão (CE, v/v) e produtividade de grãos (PROD, $\mathrm{kg} / \mathrm{ha}$ ) em nove cultivares de milho-pipoca.

\begin{tabular}{lcccccccc}
\hline Cultivar & NE & EF & PLF & EMP $^{(1)}$ & PED & P100 & CE & PROD \\
\hline Beija-flor & 37 & 31 & 1,2 & 1,5 & 30 & 15,2 & 14,9 & 2.559 \\
Branco & 43 & 36 & 1,2 & 1,7 & 10 & 14,8 & 18,0 & 3.213 \\
CMS 42 & 35 & 32 & 1,1 & 2,1 & 10 & 14,4 & 12,4 & 3.202 \\
CMS 43 & 43 & 33 & 1,3 & 1,4 & 10 & 13,2 & 18,4 & 3.809 \\
IAC 112 & 50 & 33 & 1,5 & 1,0 & 10 & 12,5 & 24,1 & 3.468 \\
Rosa-claro & 37 & 30 & 1,2 & 2,1 & 20 & 15,2 & 12,9 & 2.664 \\
RS 20 & 27 & 34 & 0,8 & 1,3 & 20 & 10,8 & 24,4 & 1.290 \\
Viçosa & 45 & 37 & 1,2 & 2,5 & 20 & 14,7 & 17,2 & 3.385 \\
Zélia & 39 & 35 & 1,1 & 1,6 & 10 & 11,6 & 26,0 & 2.672 \\
\hline Média & 40 & 33 & 1,2 & 1,7 & 16 & 13,6 & 18,7 & 2.918 \\
\hline QM Tratamentos $^{\text {n }}$ & $191,0^{* *}$ & $16,3^{\text {ns }}$ & $0,0524^{* *}$ & $0,00949^{*}$ & $0,0325^{\text {ns }}$ & $23,778^{* *}$ & $15,230^{* *}$ & $441.832^{* *}$ \\
\hline CVg $^{(2)}$ & 15,9 & - & 14,6 & 20,3 & - & 10,5 & 25,7 & 26,0 \\
\hline $\mathrm{CVe}^{(3)}$ & 9,1 & 9,0 & 12,0 & 27,9 & 93,4 & 7,4 & 15,0 & 14,4 \\
\hline
\end{tabular}

(1) 1: espiga completamente empalhada; 2: pequena abertura da palhada na ponta da espiga, sem expor o sabugo; 3 : sabugo exposto na ponta da espiga; 4: presença de grãos expostos na ponta da espiga; 5: ampla exposição de grãos com ampla abertura da palhada. ${ }^{(2)} \mathrm{CVg}$ : coeficiente de variação genético. ${ }^{(3)} \mathrm{CVe}$ : coefíciente de variação experimental. ns Não-significativo. * e **Significativo a $5 \%$ e a $1 \%$ pelo teste $\mathrm{F}$, respectivamente. 
Tabela 3. Variáveis canônicas obtidas da análise das variáveis originadas da transformação, por condensação pivotal, das variáveis originais e suas respectivas variâncias e a importância das características do milho-pipoca nos autovetores.

\begin{tabular}{lrcc}
\hline $\begin{array}{l}\text { Variáveis } \\
\text { canônicas }\end{array}$ & Variância & $\begin{array}{c}\text { Variância } \\
\text { acumulada (\%) }\end{array}$ & \begin{tabular}{c} 
Importância das características nos autovetores $^{(1)}$ \\
\hline VC1
\end{tabular} \\
VC2 & $2.181,17$ & 60,247 & $\mathrm{AE}$ \\
VC3 & $1.314,39$ & 96,558 & $\mathrm{NP}$ \\
VC4 & 84,98 & 98,900 & $\mathrm{AE}$ \\
VC5 & 24,89 & 99,587 & $\mathrm{NP}$ \\
VC6 & 10,20 & 99,870 & $\mathrm{AE}$ \\
VC7 & 2,85 & 99,940 & $\mathrm{NP}$ \\
VC8 a VC19 & 1,31 & 99,980 & $\mathrm{AE}$ \\
\hline
\end{tabular}

(1)AE: altura de espigas; NP: número de plantas; PLF: prolificidade; HT1: severidade de helmintosporiose no florescimento; AP: altura de plantas.

As cultivares podem ser agrupadas de acordo com a distância no plano cartesiano (Figura 1). Assim, cultivares dentro dos grupos arbitrários apresentam maior similaridade do que as cultivares que estão em diferentes regiões circuladas.

A análise das variáveis canônicas permite o descarte daquelas características que pouco contribuíram para a variabilidade genética entre as cultivares avaliadas, possibilitando economia de tempo, mãode-obra e recursos financeiros em futuros estudos (Cruz \& Regazzi, 1994). Podem ser descartadas características que apresentam o maior coeficiente de ponderação nas variáveis canônicas menos importantes, ou seja, nas últimas variáveis como o estande, a prolificidade e a altura da espiga. As características dispensáveis em estudos de divergência genética são aquelas com poucas variações entre as cultivares ou redundantes por estarem correlacionadas com outras características, como altura de plantas e de espigas. A baixa variação da característica estande de plantas foi ratificada pela não significância das cultivares na análise de variância. No entanto, o estande, em muitos casos, é utilizado para corrigir a produtividade de grãos, por isso sugere-se que esta característica continue a ser avaliada.

As estimativas das distâncias generalizadas de Mahalanobis (D2) indicaram os pares de cultivares mais distantes geneticamente, RS 20 e Beija-flor e Rosa-claro e RS 20, e os pares de cultivares mais similares geneticamente, IAC 112 e Viçosa e Branco e CMS 42

A análise de agrupamento dividiu as nove cultivares em três grupos geneticamente dissimilares:

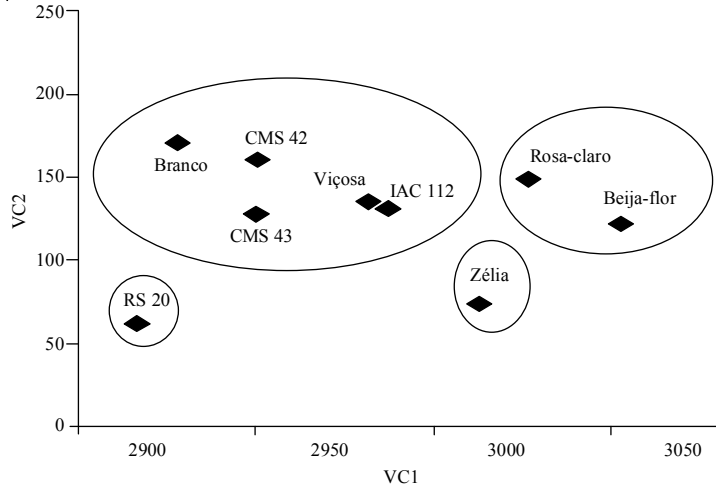

Figura 1. Dispersão das noves cultivares de milho-pipoca em função das variáveis canônicas (VC1 e VC2).

Grupo I (IAC 112, Viçosa, CMS 43, CMS 42, Branco e Rosa-claro), Grupo II (Beija-flor e Zélia) e Grupo III (RS 20). As cultivares oriundas de programas de melhoramento ou regiões semelhantes mostraramse mais semelhantes, como CMS 42 e CMS 43, pertencente à Embrapa, e Viçosa, Branco e Rosa-claro, à Universidade Federal de Viçosa. A RS 20 ficou em grupo separado, por apresentar características relacionadas às plantas bastante diferentes das demais cultivares. Por não terem sido considerados na análise de divergência, cultivares com grãos brancos (CMS 43), amarelos e rosas (Rosa-claro) apresentamse no mesmo grupo; no entanto, comercialmente, estas cultivares apresentam valores distintos, sendo preferido o grão de cor amarela seguido pelo de cor branca. $\mathrm{O}$ de cor rosa não apresenta valor comercial. 
Houve concordância parcial entre a dispersão gráfica e o método de otimização de Tocher quanto ao agrupamento das cultivares (Figura 1). Somente a cultivar Beija-flor não foi agrupada com Zélia nos dois métodos. No presente trabalho, a técnica da dispersão gráfica foi semelhante e de fácil interpretação, como o agrupamento de Tocher, diferente de Miranda et al. (1999), que trabalhou com 36 linhagens de feijão-mungo e três variáveis canônicas, e concluíram que a dispersão gráfica foi de mais difícil interpretação do que o agrupamento de Tocher.

As diferentes técnicas de classificação dos mesmos genótipos sejam com informações genealógicas, moleculares ou agronômicas, devem apresentar resultados similares se as classificações refletirem a verdadeira associação entre os valores genotípicos (Mumm et al., 1994).

Segundo Hallauer \& Miranda Filho (1981), devese preferir cruzamentos entre populações ou genitores que apresentem altas médias e divergência ampla nas características de interesse. No entanto, se houver a necessidade de se optar entre uma população com média de produção intermediária e ampla diversidade, ou outra com alta produção e diversidade intermediária, deve-se preferir esta última. O trabalho dispensado para aumentar a produção nesta população, com a finalidade de alcançar níveis produtivos de determinada população com média alta, não é compensador, apesar dos maiores ganhos genéticos nos primeiros ciclos de seleção. Assim, o potencial de melhoramento das cultivares foi determinado pelas altas médias das características agronômicas mais importantes e a posição das cultivares em diferentes grupos obtidos da divergência genética.

\section{Conclusões}

1. Para melhoramento de milho-pipoca, as cultivares com maior potencial são RS 20, Zélia, IAC 112 e Beija-flor.

2. As cultivares apresentam divergência genética.

\section{Agradecimentos}

À Fapemig, pelo apoio financeiro.

\section{Referências}

ALEXANDER, D. E.; CREECH, R. G. Breeding special industrial and nutritional types. In: SPRAGUE, G. F.; FUCCILLO, D. A. (Ed.). Corn and corn improvement. Madison: American Society of Agronomy, 1977. p. $363-$ 386. (Agronomy, 18).

ANDRADE, R. A. Cruzamentos dialélicos entre seis variedades de milho pipoca. 1996. 56 f. Dissertação (Mestrado em Genética e Melhoramento) - Universidade Federal de Viçosa, Viçosa, MG, 1996.

BLEICHER, J. Níveis de resistência a Helminthosporium turcicum Pass em três ciclos de seleção em milho pipoca (Zea mays L.). 1988. 130 f. Tese (Doutorado em Fitopatologia) - Escola Superior de Agricultura Luiz de Queiroz, Piracicaba, 1988.

BRUNSON, A. M.; SMITH, G. M. Hybrid popcorn. Journal of the American Society of Agronomy, Madison, v. 37, p. 176-183, 1945.

CARNEIRO, V. Debulha, classificação em tamanho e armazenamento na qualidade de sementes de milhopipoca. 2002. 40 f. Dissertação (Mestrado em Fitotecnia) - Universidade Federal de Viçosa, Viçosa, MG, 2002.

CENTRO INTERNACIONAL DE MEJORAMIENTO DE MAÍZ Y TRIGO (México, México). Managing trials and reporting data for CIMMYT's international: maize testing program. México, 1985. $20 \mathrm{p}$.

COIMBRA, R. R. Seleção entre famílias de meiosirmãos da população DFT-1 Ribeirão de milho-pipoca. 2000. 54 f. Dissertação (Mestrado em Genética e Melhoramento) - Universidade Federal de Viçosa, Viçosa, MG, 2000.

COIMBRA, R. R.; MIRANDA, G. V.; VIANA, J. M. S.; CRUZ, C. D. Correlações entre caracteres na população de milho-pipoca DFT-1 Ribeirão. Revista Ceres, Viçosa, MG, v. 48, n. 278, p. 427-435, 2001.

CRUZ, C. D. Programa Genes. Viçosa, MG: Ed. UFV, 1997. $442 \mathrm{p}$.

CRUZ, C. D.; REGAZZI, A. J. Modelos biométricos aplicados ao melhoramento genético. Viçosa, MG: Ed. UFV, 1994. 390 p.

DOFING, S. M.; D'CROZ-MASON, N.; THOMASCOMPTON, M. A. Inheritance of expansion volume and yield in two popcorn $x$ dent corn crosses. Crop Science, Madison, v. 31, p. 715-718, 1991.

Pesq. agropec. bras., Brasília, v. 38, n. 6, p. 681-688, jun. 2003 
FANTIN, G. M.; SAWAZAKI, E.; BARROS, B. C. Avaliação de genótipos de milho pipoca quanto a resistência a doenças e qualidade da pipoca. Summa Phytopathologica, Jaboticabal, v. 17, n. 2, p. 90-99, 1991

GALVÃO, J. C. C.; SAWAZAKI, E.; MIRANDA, G. V. Comportamento de híbridos de milho-pipoca em Coimbra, Minas Gerais. Revista Ceres, Viçosa, MG, v. 47, n. 270, p. 201-218, 2000.

HALLAUER, A. R.; MIRANDA FILHO, J. B. Quantitative genetics in maize breeding. Ames: Iowa State University Press, 1981. 468 p.

LARISH, L. B.; BREWBAKER, J. L. Diallel analyses of temperate and tropical popcorn. Maydica, Bergamo, v. 44, p. 279-284, 1999.

LINARES, E. Seleção recorrente recíproca em famílias de meio-irmãos em milho pipoca (Zea mays L.). 1987. 78 f. Dissertação (Mestrado em Genética e Melhoramento de Plantas) - Escola Superior de Agricultura Luiz de Queiroz, Piracicaba, 1987.

LIRA, M. A. Seleção entre e dentro de famílias de meio-irmãos para produção e capacidade de expansão e correlações entre alguns caracteres em milho pipoca (Zea mays L.). 1983. 63 f. Dissertação (Mestrado em Fitotecnia) - Escola Superior de Agricultura de Lavras, Lavras, 1983.

MACHADO, P. F. Efeito das condições de colheita e secagem sobre a capacidade de expansão de milhopipoca. 1997. 41 f. Dissertação (Mestrado em Engenharia Agrícola) - Universidade Federal de Viçosa, Viçosa, MG, 1997.

MELCHINGER, A. E. Genetic diversity and heterosis. In: COORS, J. G.; PANDEY, S. (Ed.). The genetics and exploitation of heterosis in crops. Madison: Crop Science of America, 1999. p. 99-118.

MIRANDA, G. V.; COELHO, A. D. F.; SHIMOYA, A.; COIMBRA, R. R.; SANTOS, I. C. Divergência genética de linhagens de feijão-mungo (Vigna radiata (L.)) Wilczeck. Revista Ceres, Viçosa, MG, v. 46, n. 265, p. 309-319, 1999.
MIRANDA, G. V.; SOUZA, L. V.; FIDELIS, R. R.; GODOY, C. L.; COIMBRA, R. R.; MELO, A. V. de; GUIMARÃES, L. J. M. Reação de cultivares de milhopipoca a helmintosporiose. Revista Ceres, Viçosa, MG, v. 49 , n. 285 , p. 513-521, 2002.

MUMM, R. H.; HUBERT, L. J.; DUDLEY, J. W. A classification of $148 \mathrm{U}$. S. maize inbreds - II: validation of cluster analysis based on RFLPs. Crop Science, Madison, v. 34, p. 852-865, 1994.

NAMORATO, H.; MIRANDA, G. V.; DONÁ, A. A.; FALUBA, J. S.; GODOY, C. L.; SOARES, M. O. Análise multivariada AMMI BIPLOT aplicada à interação genótipos x ambientes. In: CONGRESSO NACIONAL DE MILHO E SORGO, 24., 2002, Florianópolis. Anais... Florianópolis: Epagri/Embrapa-CNPMS, 2002. 349 p.

PACHECO, C. A. P.; GAMA, E. P.; GUIMARÃES, P. E. O.; SANTOS, M. X.; FERREIRA, A. S. Estimativas de parâmetros genéticos nas populações CMS-42 e CMS-43 de milho pipoca. Pesquisa Agropecuária Brasileira, Brasília, v. 33, n. 12, p. 1995-2001, dez. 1998.

PEREIRA, M. G.; AMARAL JÚNIOR, A. T. Estimation of genetic components in popcorn base on the nested design. Crop Breeding and Applied Biotechnology, Londrina, v. 1, p. 3-10, 2001.

RAO, C. R. Advanced statistical methods in biometric research. New York: J. Wiley, 1952. 390 p.

SAWAZAKI, E. Melhoramento do milho-pipoca. Campinas: Instituto Agronômico, 1995. 21 p.

SAWAZAKI, E. Parâmetros genéticos em milho-pipoca (Zea mays L.). 1996. 157 f. Tese (Doutorado em Genética e Melhoramento de Plantas) - Escola Superior de Agricultura Luiz de Queiroz, Piracicaba, 1996.

ZANETTE, V. A. Análise da variabilidade genética em populações de milho pipoca (Zea mays L.): heterose da capacidade de expansão do grão. Agronomia Sulriograndense, Porto Alegre, v. 25, n. 2, p. 173-181, 1989.

ZINSLY, J. R.; MACHADO, J. A. Milho-pipoca. In: PATERNIANI, E.; VIÉGAS, G. P. Melhoramento e produção do milho. 2. ed. Campinas: Fundação Cargill, 1987. p. 413-421. 